\title{
THE SOCIAL MEDIA USER: A THEORETICAL BACKGROUND TO THE DEVELOPMENT OF SOCIAL MEDIA USER TYPOLOGY
}

\begin{tabular}{|l|l|}
\hline MS. KRITHIKA G K & DR. SANJEEV KUMAR K.M \\
Research Scholar, Department of Management, & Professor and Dean, Faculty of Commerce and \\
Akkamahadevi Women's University, Vijayapura, & Management, Akkamahadevi Women's University, \\
and Assistant Professor, National Institute of Fashion & Vijayapura, Karnataka, India \\
Technology (NIFT), Bengaluru, Karnataka, India & sanjeevkarnaik@ gmail.com \\
krithikagk@gmail.com & \\
\hline
\end{tabular}

\begin{abstract}
Social media has become an all pervading phenomena in the online digital world and an indispensable part of our daily lives. They have changed the way people communicate, connect and participate. The advent of affordable smartphones and accessible internet connectivity has accentuated its growth and made it pervasive across all echelons of human society. This is the reason why they are good platforms for businesses and brands to reach out to their existing and potential consumers. Inorder to make use of these cost-efficient platforms marketers need to know how involved people are in these online media. The purpose of this research was to understand the usage and types of social media users by reviewing of available literature. Through this research it is clear that social media usage can be classified in to four major categories based on individuals need for gratification - socialising, expressing, recreation and information. It can also be inferred from this study that the most user typologies that have been developed in earlier studies are based on one or more of the following three dimensions (1) Reason for using of Social Media, (2) The level of activity or involvement and (3) The variety of social media applications used. These insights will help marketers to strategize their marketing efforts to reach out to their target market on online platforms.
\end{abstract}

Keywords: internet, social networking sites, social media, users, involvement, gratification, typology

\section{INTRODUCTION}

The pervasiveness of social media has changed the way people communicate. It has become such an important part of the daily lives of people that they contribute a considerable amount of their daily time to be on their social media accounts. Social media as we know it is actually an amalgamation of two words social and media where 'social' refers to a two way interaction with people which involves sharing and receiving of information and 


\section{ELK ASIA PACIFIC JOURNAL OF MARKETING \& RETAIL MANAGEMENT}

ISSN 2349-2317 (Online); DOI: 10.16962/EAPJMRM/issn. 2349-2317/2018; Volume 9 Issue 4 (2018) 'media' refers to the mechanisms of way to attract and engage present and communication in this context mainly the internet and internet-centered platforms and portals (Nations 2016). According to Taylor (2016) the Social Media Producer at the World Economic Forum, the top ranking social media networks based on popularity of usage are Facebook, Instagram, Twitter, Linkedin and Snapchat. These expanding platforms have been grouped into six primary categories, each having a distinctive set of characteristics. They are (1) social networks (Facebook), (2) bookmarking sites (StumbleUpon), (3) social news (reddit), (4) media sharing (YouTube), (5) microblogging (Twitter) and (6) blog, comments and forums (Google's Blogger) (SEOPressor, 2018).

It must be noted that all social media platforms are centered on relationships. They are based on shared participation of its consumers and are enabled with the help of technology. Its complexity is due to the sheer number and variety of channels and vehicles being launched in the web space all the time (Tuten \& Solomon, 2016).

Social media platforms were developed to connect the customers. Now they are looked upon as opportunities for businesses to engage customers and build brands, thereby creating a lot of curiosity and interest in them. They offer an effective potential customers (Halligan and Shah, 2010). Social media also encourages interaction between consumers and brands (Tuten, 2008). Likewise, customers can communicate with other customers, share information about the products and services, and thereby influence each other's buying decisions (Mangold \& Faulds, 2009; Gunelius, 2011). Thus, social media generates prospects for creating brand awareness, recognition, and loyalty (Çiçek \& Eren-Erdoğmuş, 2013). But their growing numbers, size and complexity involved in understanding them and their users create a lot of challenges to the marketer. According to an analysis by Boyd and Ellison (2007), even scholars have a limited understanding of who is using these sites, why they are using it, and for what purposes, especially outside the USA. Moreover understanding why people use social media platforms would provide organizations with guidance when designing services for their clients (Hallikainen, 2015). Drawing up successful marketing strategies, require a good understanding of social media users and their behaviour. So the purpose of this research is to gain clarity on the "who" and "why" of the different kinds of social media users based on the literature reviewed.

\section{LITERATURE REVIEW}




\section{ELK ASIA PACIFIC JOURNAL OF MARKETING \& RETAIL MANAGEMENT}

ISSN 2349-2317 (Online); DOI: 10.16962/EAPJMRM/issn. 2349-2317/2018; Volume 9 Issue 4 (2018) Literature on what people do on social information, debating, socializing, or for media and the extent of involvement in the media based on which user types have been determined, have been reviewed as below.

\subsection{Use and Users of Social Media:}

Owing to the exponential growth of the internet, users are more diverse and elusive in their usage. Moreover modern mobile equipment, like smartphones, have increased the complexity and the dimensions of the internet and social media usage, since they can be taken with the users everywhere and transactions can be conducted at any time (Krairit, 2018). Using social media has become a part of the daily routine of people. It is used by the general public as well as businesses. Social networking sites (SNSs) or social media networks have become an integral part of the young generation's social lives, for others these platforms that are used for purposes like searching for information (Hallikainen, 2015). In the United States of America, 177 million adults over 18 years of age access social media on smartphones followed by 74 million on tablets, then personal computers. Adult users spend between four to six plus hours on the social media, that accounts 20 to $24 \%$ of their internet time. At 6.33 hours women spend the most time on social platforms (Nielsen, 2017). Social media or SNSs are used in several different ways, including accessing entertainment (Valenzuela, Park \& Kee, 2009). There were 11 reasons and subreasons for using social networking platforms but the main motivating reasons for using them were to contact new people (31\%), keep in touch (21\%), just socialising $(14 \%)$ and information (10\%) (Brandtzaeg $\&$ Heim, 2009). Web media users perceive social media as an additional path to traditional media and express their preference for using social media due to the features it offers over traditional media like the variety of information it offers, the freedom to view information of their choice, exposure to different perspectives, availability of direct information from the source \& deeper background information about a topic and the interactivity between viewers and content (Beheshti-Kashi \& Makki, 2013).

The view of gratifications approach to understanding the use of social media proposes that users actively choose the media that best fulfills their needs. This approach looks upon users being active, their choices in using media are based on their past media exposure and experiences and the gratification that they have received from these past experiences (Lazarsfeld \& Stanton, 1942; Blumler \& Katz, 1974). Going by what Groebel, (1997) says, the actual choice of media may vary depending 


\section{ELK ASIA PACIFIC JOURNAL OF MARKETING \& RETAIL MANAGEMENT}

ISSN 2349-2317 (Online); DOI: 10.16962/EAPJMRM/issn. 2349-2317/2018; Volume 9 Issue 4 (2018)

on functional, situational, and personal factors influencing users.

The usage of such sites differs from person to person, and their different patterns of usage can have different social implications. SNS usage involves systematic patterns in which the same SNS can be used for different purposes, and different SNSs can be used for the same purpose (Brandtzæg \& Heim, 2011). According to Hallikainen (2015) continued use of social media platforms increase one's perception of the social capital available from the network and this in turn enforces the continued use of such platforms. Consumers use social media to get information about products and services, participate in promotions, support favourite brands, rate and review products and access events that are restricted to 'VIPs' or members only (Nielsen, 2017). The usage of SNS however has been identified based on the users' interactions on specific SNSs (e.g. MySpace, Flickr, YouTube, Twitter, LinkedIn, or Facebook), or on basic measurements and an understanding of usage in terms of frequency measures that often use only two possible outcomes (e.g., heavy use or low use) (Brandtzæg \& Heim, 2011).

\subsection{Social Media User Typologies:}

Consumer typologies are effective mechanisms for identifying and addressing different consumer clusters. Marketers have been dealing with heterogeneity in the market by segmenting it and developing typologies (Barczak et al., 1997; Burnham et al., 2003). Identifying and profiling customers based on their social media use and involvement are useful to marketers. It helps them target the right \& relevant audience. According to the compilation of Brandtzæg \& Heim (2010), there are at least 10 studies on Internet user typologies from 2008 to 2010 and most of them are related to the western world.

Some of the social media related user typologies from various studies are described below.

A study by Nielsen (2006) segmented social media users into three categories. (1) Lurkers: they constitute $90 \%$ of the sample and just read and observe activities on social media but not participate in any. (2) Intermittent Contributors: who participate from time to time i.e. occasionally. (3) Heavy Contributors: they are just $1 \%$ of the sample, and are very involved and actively contribute and participate on to social media networks. $90 \%$ of postings are made by this $1 \%$ of the sample. This is kind of participative inequality has its disadvantages since this $1 \%$ is represented 


\section{ELK ASIA PACIFIC JOURNAL OF MARKETING \& RETAIL MANAGEMENT}

ISSN 2349-2317 (Online); DOI: 10.16962/EAPJMRM/issn. 2349-2317/2018; Volume 9 Issue 4 (2018) on most platforms and the rest $90 \%$ is not on the Internet to keep in pace with others; heard at all, this poses a challenging situation for marketers.

\section{Forrester (2007) categorised Social} the Faithfuls, who search up to connect with old friends on the Internet; and the Functionals, who make use of the Internet Computing behaviours into a ladder with six levels of participation, based on a method they termed as Social Technographics ${ }^{\circledR}$ in order to describe a population according to its various levels of participation in social media related activities like publishing, uploading, commenting, tagging, community activities, reading watching and listening. These user categories were Creators (13\%), Critics (19\%), Collectors (15\%), Joiners (19\%), Spectators (33\%) and Inactives $(52 \%)$ However user participation at one level may or may not have overlapped with participation at other levels (Li et.at. 2007). They have used this categorisation to understand user in various countries and continents in their later researches as well as mentioned later in the literature review.

\section{A study by British's Office of} Communication (OFCOM) in 2008 used exploratory methods to categorised users into five types based on the user behaviours. The are - the Alpha Socializers, who are regular users but with short spurts; they are attention seekers, who pursue attention and comments from others; the Followers, who follow what other are doing

to fulfil a particular purpose.

A study by Shao (2009) groups social media users in to three categories based on their activities owing to individual motivations like (1) consumption for information and entertainment; (2) participation for social interaction and group building; and (3) creation of content for self-expression and self- realization. The three categories are: Consuming - The users (consumers) only watch or read social media content created by others but they never participate. Participating - The users participate on social media through useruser interaction and user-content interaction like content sequencing, making additions to the playlist, sharing content with others, posting comments etc. But they are not engaged in any real content creation so they are just participators. Producing The users (producers) actually create content in the form of posting personal stuff, like texts, images, tapes, and videos. They do this inorder to express themselves and for self-realization. The users could demonstrate or be motivated by more than one of these above described behaviours at the same time. It was also noticed that 


\section{ELK ASIA PACIFIC JOURNAL OF MARKETING \& RETAIL MANAGEMENT}

ISSN 2349-2317 (Online); DOI: 10.16962/EAPJMRM/issn. 2349-2317/2018; Volume 9 Issue 4 (2018) social media users consist mostly of one of the biggest user categories consisting "consumers" followed by "participants."

Brandtzaeg and Heim (2010) have reviewed 22 studies and 5 theories between the period of 2001 to 2010 in the area of internet and social media users and usage patterns. Based on the comprehensive literature review Brandtzaeg has reorganised all of the user groups of their previous studies into eight groups, based on similarity of characteristics and renamed them according to his own terms. He grouped the user types - debaters, contributors and creators in his previous studies under the term, debaters. Interactors, on-off shoppers, lurkers and tourists were termed lurkers. These eight user types are described in the table that follows: Non-Users - the most common category of users across categorisations. Sporadics - users who are newcomers and are low-level or sporadic users on the platforms they use (based on 20 studies). Debators - consisted of bloggers and debaters in social networks, a growing user segment owing to easier access and convenient for blogging, discussion and debating. Entertainment Users - a probably growing user type because of increase in user gaming activities (based on 10 studies). Socialisers - an increasing segment owing to growing social media applications (based on 9 studies). Lurkers - of users who use social media by lurking on them to pass time or window shop. (identified in five studies). Instrumental Users - a common user segment consisting of users who use digital media for utility purposes as an information tool for both personal and professional user. Not so obvious in social networks. They were identified in 16 studies. Advanced Users like sporadics, this is the most common user category. Users exhibit a wide range of media frequently, using the most advanced tools \& facilities compared to the rest of the user population (based on 20 studies).

A later research paper by Brandtzaeg \& Heim in 2011, analysed survey data from 5,233 respondents on four major Norwegian Social Networking Sites and identified and condensed his earlier eight user types to just five distinct user types: 1) Sporadics (19\%): users spread across all age categories, who make sporadic or infrequent visits to the media, mainly checks status, use social media just to keep in touch and is not involved in producing user-generated content (UGC) 2) Lurkers (27\%): are the largest category of users with low participation, mostly females, they are recreation seekers, use social media for recreation and to kill time than for socialising. 3) Socialisers (25\%): are characterised by high level of user 


\section{ELK ASIA PACIFIC JOURNAL OF MARKETING \& RETAIL MANAGEMENT}

ISSN 2349-2317 (Online); DOI: 10.16962/EAPJMRM/issn. 2349-2317/2018; Volume 9 Issue 4 (2018) participation, mostly female, have more characterised by replies, retweets and contacts, use media to keep in touch and make new friends, make 'small talk', post comments and post pictures. 4) Debaters (11\%): are heavy socialisers with high involvement in reading, writing and taking part in discussions, they are older than other categories, there is negligible difference in media usage between the genders, they use the media for information on events, publications and experiences, as well as to socialise. 5) Actives (11\%): consist of mainly young females, participate in all kinds of user activities on social media, use SNS mainly for socialising with friends in their profile. They publish and upload pictures, activities, usually related to events and publishing music or videos and open to creating UGC.

A later study by Forrester in 2010 in the United States, clearly indicated that the types of social activities that the individuals were engaged in have been consistent even after six years from their initial study. The report by Forrester in 2007 (mentioned earlier) had also continued with the same typologies. I this study they even uncovered a new kind of behaviour of holding "rapid conversations" that was being exhibited by the participants through social media platforms like Twitter and mostly Facebook. These so called "rapid conversational interactions were hashtags". Owing to which they have even added a new category called "Conversationalists" to their "Social Technographics Ladder" now taking it to seven user types. (Bernoff, 2010).

In another global study on Social Technographics conducted by Forrester (2012) in 15 countries covering North America, Europe, Metropolitan Asia and Latin America where social media is used regularly, classified internet and social media users into seven categories as before, depending on frequency and preference of use of social computing activities (Fleming, Gina; Elliot, Nate, 2012). The summarised description of user involvement in Social Technographics categories are given as follows: Creators - publish blogs, publish web pages, create and upload a music, audios and videos, write $\&$ post articles or stories. Conversationalists - update status and post other updates on social networking sites like Facebook and Twitter. Critics comment on blogs, post ratings and reviews about products and services, contribute content to online forums, contribute to or edit articles in a wikis. Collectors - use RSS (Rich Site Summary) feeds, tag web pages or photos, may vote for websites through online platforms. Joiners - use social networking sites, maintain them and visit them. Spectators - read blogs, read content 


\section{ELK ASIA PACIFIC JOURNAL OF MARKETING \& RETAIL MANAGEMENT}

ISSN 2349-2317 (Online); DOI: 10.16962/EAPJMRM/issn. 2349-2317/2018; Volume 9 Issue 4 (2018) on online forums and tweets, watch peerentertainment, keeping in touch with generated videos, listen to podcasts. Inactives - not involved in any of the above activities.

A study conducted in Spain used the latent segmentation approach to classifiy and profile social networking sites (SNSs) users based on frequency of user activity on the SNSs, socio-demographic variables, SNS related experience and dimensions of their patterns of interaction. It has been noticed that user activites in segments do overlap. Through their research they obtained a SNS user typology consisting of four segments as described below (Alarcon-del-Amo, Lorenzo-Romero, \& Gomez-Borja, 2011). Introvert User - the smallest and least active segment of users, who use SNS infrequently, to just send private messages and update their profiles. This segment consists of mainly men who are over 50 years of age, who spend less than an hour on SNS and mostly have just one SNS account. Novel User - the segment consists of $25 \%$ of users, majorly women aged less than 29 years old, having at least two media accounts with higher per week usage time and higher frequency on SNS than 'introverts' They use social media to send private and public messages, make comments, send and label pictures, update profile, search for information and browse profiles. This segment uses social media for friends. Versatile User - The largest segment with around $36 \%$ users, mostly men in the age group of 36 to 44 years who connect at least once a day, spend one to five hours a day on social media, have at least two to three media accounts with private $\&$ public profiles and having 10 to 100 contacts. They performing intense and diverse activities on SNS, apart from doing what 'novels' do, they communicate ideas / reflections, follow, share useful information and share and even use social media for maintaining and building professional contacts. ExpertCommunicator User - The segment consists of $20 \%$ of social media users who are most active and very experienced in SNS use, majorly women between 25 to 35 years of age. They use SNS very frequently, spend more time on social media and involved in a variety of activities. They more involved than the 'versatiles'. This group uses social networking sites for entertainment, making new offline friends (they have more than 100 contacts), forming groups of interest, get updated about parties, events, products and happenings.

A Turkey based study on social media users has classified users into five clusters. (1) Inactives: who do not use any social media applications, are mostly male, married persons, $60 \%$ between 18 to 34 years of age 


\section{ELK ASIA PACIFIC JOURNAL OF MARKETING \& RETAIL MANAGEMENT}

ISSN 2349-2317 (Online); DOI: 10.16962/EAPJMRM/issn. 2349-2317/2018; Volume 9 Issue 4 (2018) and a higher percent over 45years. (2) characteristics that are very different from Sporadics/Rares: a group younger than inactives, second largest married group, infrequently use social networking and content sites, rarely use blogs and forums and inactive on virtual platforms. (3) Entertainment Users: a cluster that shows average use of virtual communities, content communities and social networking sites for entertainment, are majorly single, male and high school goers. (4) Debaters: this cluster uses most social media tools like forums, blogs, Social networking sites, microblogging sites mainly Twitter and content sites, but not virtual sites. They were mostly undergraduate or graduate students with no noticeable differences in gender, income and marital status. (5) Advanced Users: are made up of $65 \%$ of high school students who actively use all social media applications again made up of mainly single, male users less than 18 years (Çiçek \& Eren-Erdoğmuş, 2013).

One of the recent researches conducted in Thailand had explored the relevance of user typology mentioned in previous studies. The results revealed that previous activity based categorisations may alone not be very relevant in grouping users. The study classifies users into four new user types based on the methodology used in the research. The research suggests that three of the new groups of users that have 


\section{ELK ASIA PACIFIC JOURNAL OF MARKETING \& RETAIL MANAGEMENT}

ISSN 2349-2317 (Online); DOI: 10.16962/EAPJMRM/issn. 2349-2317/2018; Volume 9 Issue 4 (2018) The researcher calls the above three groups

indicated above as self-satisficing groups, based on the economic concept of 'Satisfying' as, the users of this generation, use applications or accounts as necessary to "suffice and satisfy their needs" based on their own interests and will.

One of the most recent researches by Nielsen (2017) in the United States of America, using a hybrid methodology combining census level of accounting of pages and videos viewed using Neilsen's Electronic Mobile Measurement tags and other appliations, categorised social media users based on the overall time spent by persons on social media. So there are Heavy Social Media Users, who spend more than three hours a day on social media networks; Medium Social media users, who spend on to two hours daily on social media; Low Social Media Users, spending less than an hour a day on social media platforms and the Non Social Media Users who do not use social media at all. The research also studied the demographics and different kinds of social, brand and purchase related activites that the different user categories are engaged in.

\section{RESEARCH METHODOLOGY:}

This study is exploratory in nature and founded on reviewing of latest available literature on social media user typologies.
The two main objectives of this study are to (1) Identify the usage of social media and types of social media users and (2) Determine the basis for user categorisation in existing user typologies

The scope of the study is pertaining to the review of existing and available literature on the internet and social media user, their media usage and most importantly the different user typology, that emerged from previous studies on user types.

\section{FINDING \& DISCUSSION:}

There is rapid change taking place in the digital world, the launch of web 2.0 technologies has led to quantum increase in social networking and media involvement. It is interesting to see how people are engaged on digital social media. The literature reviewed has provided a deep insight into the users and usage of social media. Some of the key insights from this study is that most researches on social media are pertaining to the more developed countries mainly the United States of America, parts of Europe, Turkey and some parts of Asia.

Social media is centered on relationships, but their use is not limited to socialising. The major findings drawn from the literature reviewed are, that most, if not all users on social media actually use if for 


\section{ELK ASIA PACIFIC JOURNAL OF MARKETING \& RETAIL MANAGEMENT}

ISSN 2349-2317 (Online); DOI: 10.16962/EAPJMRM/issn. 2349-2317/2018; Volume 9 Issue 4 (2018) gratification of their personal as well as reviewed. The number of typologies that work related needs. The usage of social media can be classifies in to four major categories or utilitarian functions they serve - Socialising, Expressing, Recreation and Information. The descriptions of the uses are as below:

Socialising: making new friends and keeping in touch with existing friends.

Expressing: this includes seeking attention from others, it is based on what is expressed or communicated in the form of sharing of opinions, thoughts and feelings through posting comments, providing information, discussing, blogging, rating, reviewing, posting pictures, audios, videos etc.

Recreation: joining groups of interest, playing games, reading and watching content created by others

Information: getting news and information through social media, by keeping up with what others are doing, checking out profiles of others, getting news and seeking, product, service and promotion related information

Though the patterns of usage of social media users is varied, the users seek gratification by accomplishing what they seek, by joining and being on social media platforms.

In this study 12 previous researches on internet and social media typologies during the period 2006 to 2017 have been have emerged from the studies range from three types (Neilsen, 2006) to eight types (Brandtzaeg and Heim (2010) of users. It can be inferred from the literature reviewed that most of the user typology categorisations are founded on one or more of the following three dimensions:

(1) Reason for using of Social Media: which includes the four utilitarian functions - Social, Expressive, Recreation and Informational

(2) The level of activity or involvement (low, medium or high): it includes the frequency of media access and participation, and the time spent on the media platform involved and

(3) The variety of social media applications used (low, intermediate, high): this includes the number of different internet or social media platforms used as well as the social media participation tools and skills used

There are many similarities in the methodology of research used by the researchers. Studies have also indicated that, there may be overlap of activities across user categorisations and there is migration of users from one segment to higher segments which involve more participation in media. Like, joining social media as 'sporadics' and later on moving to become 'socialisers', 'debaters' and 


\section{ELK ASIA PACIFIC JOURNAL OF MARKETING \& RETAIL MANAGEMENT}

ISSN 2349-2317 (Online); DOI: 10.16962/EAPJMRM/issn. 2349-2317/2018; Volume 9 Issue 4 (2018) 'actives' (Brandtzaeg \& Heim, 2011). This

is validated by the fact that there is noticeable change in the size and structure of the user categories studies over the years as depicted by the studies conducted by Forrester (2007, 2010 and 2012) and Brandtzaeg \& Heim (2009, 2010 and 2011).

\section{CONCLUSION}

According to Gallaugher and Ransbotham (2010), the business application of social media is still in its infancy and is more about presence on the platform, than integrating it as part of daily business processes. The researchers also mention that businesses are likely to move through different stages with respect to their social media maturity. This research is a small step towards gaining an understanding of users and usage of social media and the foundations of developing user typology which will go a long way in helping businesses gain social media maturity to be able to identify user groups to focus their online or social media marketing activities on for better growth prospects. This study also opens avenues for further research on social media user typology supported by exploratory and descriptive research in developing countries. These studies may either validate the existing research or provide new and deeper insights, which may be valuable to the researchers and businesses.

\section{REFERENCES}

Alarcon-del-Amo, M.-d.-C., LorenzoRomero, C., \& Gomez-Borja, M.-A. (2011). Classifying and Profiling Social Networking Site Users: A Latent Segmentation Approach. CYBERPSYCHOLOGY, BEHAVIOR, AND SOCIAL NETWORKING, 547 - 553. doi: 10.1089/cyber.2010.0346

[1] Beheshti-Kashi, S., \& Makki, B. (2013, April).

SOCIALMEDIANEWS: MOTIVATION, PURPOSE AND

USAGE. International Journal of Computer Science \& Information Technology (IJCSIT), 5(2).

[2] Bernoff, J. (2010). Introducing the New Social Technographics. Cambridge, MA: Forrester Research Inc.

[3] Blumler, J.G. and Katz, E. (1974), The Uses of Mass Communication, Sage, Beverly Hills, CA.

[4] Brandtzaeg, P. B., \& Heim, J. (2009). Why do people use social networking sites. ResearchGate. doi:10.1007/978-3-642-027741_16

[5] Brandtzæg P.B. and Heim J.(2010) 'Social network sites - A typology of users', Journal of Web-Based Communities, vol. 6, no. 3, pp. 231253. 


\section{ELK ASIA PACIFIC JOURNAL OF MARKETING \& RETAIL MANAGEMENT}

ISSN 2349-2317 (Online); DOI: 10.16962/EAPJMRM/issn. 2349-2317/2018; Volume 9 Issue 4 (2018)

[6] Brandtzæg, P.B. and Heim, J.

[13] Halligan, B. and Shah, D.

(2011) 'A typology of social networking sites users', Int. J. Web

Based Communities, Vol. 7, No. 1, pp.28-51.

[7] Çiçek, M., \& Eren-Erdoğmuş, İ. (2013, November 3). Social media marketing: exploring the user typology in Turkey. International Journal for Technology Marketing, $8(3)$.

[8] C. Li, J. Bernoff, R. Fiorentino and S. Glass, Social technographics mapping participation in activities forms, Forrester, New York, A Forrester Research Report, 2007.

[9] Fleming, Gina; Elliot, Nate. (2012). Global Social Media Adoption in 2011. Forrester Research Inc.

[10] Gallaugher, J., Ransbotham, S.: Social media and customer dialog management at starbucks. MIS Q. Exec. 9, 197-212 (2010) media development: stability and change in communication behaviour", Trends in Communication, Vol. 1, pp. 5-17.

[12] Gunelius, S. (2011) 30 Minute Social Media Marketing: Step by Step Techniques to Spread the Words about your Business, McGraw-Hill, USA.

(2010) Inbound Marketing, John Wiley \& Sons, Inc., USA.

Hallikainen, P. (2015).

Why People Use Social Media

Platforms: Exploring the

Motivations and Consequences of Use. (L. e. al., Ed.) From

Information to Smart Society,

Lecture Notes in Information

Systems and Organisation, VII, 9 -

17. doi:10.1007/978-3-319-09450-

2_2

[15] Krairit, D. (2018, May).

The New Face of Internet User Typology: The Case of Thailand. Journal of Theoretical and Applied Electronic Commerce Research, 13(2), 58 - 79. doi:10.4067/S071818762018000200106

[16] Lazarsfeld, P.F. and Stanton, F.N. (Eds) (1942), Radio Research 1941, Duell, Sloan and Pearce, New York, NY. Mangold, W.G. and Faulds, D.J. (2009) 'Social media: the new hybrid element of the promotion mix', Business Horizons, Vol. 52, No. 4, pp.357-365.

Nations, D. (2017, April 20). Popular Types of Social Networking Sites. Retrieved 12 18, 2017, from Lifewire: https://www.lifewire.com/popular- 


\section{ELK ASIA PACIFIC JOURNAL OF MARKETING \& RETAIL MANAGEMENT}

ISSN 2349-2317 (Online); DOI: 10.16962/EAPJMRM/issn. 2349-2317/2018; Volume 9 Issue 4 (2018)

types-of-social-networking-sites-

3486530

[19]

09), The 99-9-1 Rule for

Participation Inequality in Social

Media and Online Communities.

Retrieved 06092018 from the

Neilsen Norman Group

https://www.nngroup.com/articles/

participation-inequality/

[20] Nielsen. (2017). 2016

NIELSEN SOCIAL MEDIA

REPORT. The Nielsen Company.

Shao, $\quad 2009$.

Understanding the appeal of usergenerated media: $A$ uses and gratification perspective, Internet

Research 19(1), 7-25.

[22] Taylor, H. (2016, April 28).

If social networks were countries, which would they be? Retrieved from World Economic Forum: https://www.weforum.org/agenda/2 016/04/facebook-is-bigger-thanthe-worlds-largest-country/

[23] The 6 Types of Social Media. (2018). (Semantics BigData Analytics (SBDA)) Retrieved from SEOPressor Connect:

https://seopressor.com/social-

media-marketing/types-of-socialmedia/

[24] Tuten, T.L. (2008) Advertising 2.0: Social Media
Marketing in a Web 2.0 World, Preager, Westport.

[25] Tuten, T. L., \& Solomon,

R. M. (2016). Social Media

Marketing 2e. New Delhi: SAGE

Publications India Pvt. Ltd.

[26] Valenzuela, S., Park, N., \& Kee, K. F. (2009). Is there social capital in a social network site? Facebook use and college students' life satisfaction, trust, and participation. Journal of ComputerMediated Communication, 14(4), 875-901.

http://onlinelibrary.wiley.com/doi/

10.1111/j.1083-6101.2009.

01474.x/full

[27] V. OFCOM, Social Networking. A Quantitative and Qualitative Research Report into Attitudes, Behaviours and Use. London, UK: Office of Communication, 2008.

[28] Wigmore, I. (Ed.). (2015, January). Millennials (Millennial generation). Retrieved December 5, 2017, from Techtarget:

WhatIs.com: http://whatis.techtarget.com/definit ion/millennials-millennialgeneration 